Article

\title{
Audience Attention and Emotion in News Filmed with Drones: A Neuromarketing Research
}

\author{
Luis Mañas-Viniegra *, Alberto García-García and Ignacio J. Martín-Moraleda \\ Department of Applied Communication Studies, Complutense University of Madrid, 28040 Madrid, Spain; \\ E-Mails: Imanas@ucm.es (L.M.-V.), algarci@ucm.es (A.G.-G.), ignmar05@ucm.es (I.J.M.-M.) \\ * Corresponding author
}

Submitted: 31 March 2020 | Accepted: 5 June 2020 | Published: 27 July 2020

\begin{abstract}
Emotional journalism is being driven by audiovisual technology such as drones, also known as unmanned aerial vehicles, which have demonstrated their usefulness in transforming objective news into news stories from a new visual perspective, facilitating access to dangerous or difficult places. They also allow for greater immersion by an audience that has become an active participant in the news, and they contribute to the storytelling of communication despite the risk to privacy and security that their misuse might entail. The aim of this research is to determine the differences in attention and intensity of the emotions experienced when viewing two pieces of audiovisual news: One was filmed with the technological support of a drone, and the other was produced in the conventional way. The techniques of eye tracking and galvanic skin response were used in 30 Spanish university students. The results suggest that attention was focused on the most spectacular visual elements, although the images filmed with a drone received a higher concentration of attention from the subjects, and this attention was spread throughout the entire image, which demonstrates that drones enhance the effectiveness of panoramic images with natural landscapes. The greatest emotion generated by viewing the images recorded with drones was statistically significant, but it was limited exclusively to these particular scenes, and not to the entire recording of the news.
\end{abstract}

\section{Keywords}

audiovisual technology; breaking news; communication; drone; emotional journalism; eye tracking; galvanic skin response; neuromarketing; unmanned aerial vehicles

Issue

This article is part of the issue "Journalism from Above: Drones, the Media, and the Transformation of Journalistic Practice" edited by Jonas Harvard (Mid Sweden University, Sweden), Mats Hyvönen (Uppsala University, Sweden) and Ingela Wadbring (Mid Sweden University, Sweden).

(C) 2020 by the authors; licensee Cogitatio (Lisbon, Portugal). This article is licensed under a Creative Commons Attribution 4.0 International License (CC BY).

\section{Introduction}

In contrast to objective, unbiased, rational journalism (Liu, 2019) in which journalists even suppress or modify their own emotions as part of their work (Huxford \& Hopper, 2020), setting themselves up as independent observers (Wahl-Jørgesen, 2020), there is a new trend known as emotional journalism, which revolves around emotions driven by technology, as already occurs in immersive or virtual reality journalism for the purpose of reconnecting with fragmented audiences (Lecheler, 2020).
These new ways of generating news transform facts into personal experiences that create a link between the public, the news, and the journalist (Sánchez-Laws, 2017). Although journalism has always included emotion within the narration and presentation of news, this new emotional journalism, even further from news objectivity, involves audiences more emotionally and increases the attention, identification and memory of news stories (Wahl-Jørgesen, 2020).

Attention and emotion are affecting both the production and consumption of news, and more research is 
needed for both of these issues (Beckett \& Deuze, 2016). We conceive the world around us both cognitively and emotionally, which is why authors such as Orgeret (2020) have pointed out that Neuroscience can strengthen the research in this area.

Drones comprise the audiovisual technology analysed in this article, and they are capable of contributing to the development of emotional journalism, since the natural human-drone interaction (HDI) currently allows for the recognition of up to three emotional states from its recordings (Cauchard, Zhai, Spadafora, \& Landay, 2016). In short, basic information about the news is not enough to awaken the emotions of the audience, and now it is necessary to personalise the stories and represent them with images that awaken the empathic connection (Maier, Slovic, \& Mayorga, 2017).

\subsection{Journalism and Drones}

The technical name for drones is unmanned aerial vehicles, or unmanned aircraft, and they have demonstrated their usefulness in covering breaking news in dangerous locations from a new visual perspective (Holton, Lawson, \& Love, 2015), thereby enabling fast, inexpensive access to scenes where events take place (Fernández-Barrero, 2018). Drones also allow images to be captured in places that are difficult to access, and new technological developments allow for the integration of intelligent systems for the automatic identification of people or vehicles, which facilitates the recording of news in places without full visibility (Cavaliere, Loia, Saggese, Senatore, $\&$ Vento, 2019). Along these lines, it is also possible to use multi-view video systems to generate $360^{\circ}$ video images, which makes drone journalism more similar to immersive journalism (Ballout, Ghaddar, \& Wehbi, 2019). Moreover, its ability to perform wireless broadcast or point-to-multipoint transmission with $5 \mathrm{G}$ links (Sekander, Tabassum, \& Hossain, 2018) will promote the use of live connection.

Detractors highlight the risk to property, privacy and security that its misuse might entail in a regulatory context poorly adapted to new technologies (Rule, 2015). However, drones have been integrated into everyday life through devices such as smartphones, cameras, or even the drones themselves, which make up the so-called sensor society in which the capturing of data is always active (Andrejevic \& Burdon, 2015). In spite of this, some research on citizen perception has shown that there is a relatively neutral attitude toward the risk posed by drones, as they are considered neither a major threat nor a great benefit (Clothier, Greer, Greer, \& Mehta, 2015).

The fact that media audiences have become simultaneous receivers, producers and active participants (Lewis \& Westlund, 2015) is partially a result of the new interactive ways of transmitting information, as well as the new interaction between humans and technology. This interconnection has led to a voluntary renunciation of some privacy in order to obtain more per- sonalized, and consequently more satisfying content for the audience.

Even from the most quantitative journalistic point of view, the contribution of storytelling (Coddington, 2015) and emotion in professional journalism (Papacharissi, 2015) has been recognized, and drones are contributing to the creation of such storytelling from new points of view. The growing importance of images in newspaper stories has boosted digital journalism and social networks (Caple \& Bednarek, 2016), and in turn has impelled the use of 'arresting audiovisuals' as an innovative feature of added value to the news (Harcup \& O'Neill, 2017). This audiovisual perspective is where drones are capable of making a great contribution to journalism.

In short, the use of drones rapidly evolved from military use to logistics and entertainment, at which time their contribution to the media came under consideration (Tham, Selem, \& Ogulin, 2017) thanks to their novelty, recording stability, high camera resolution, and reduced price (Galvane et al., 2018), as well as their versatility ranging from panoramic shots (panning) to over-theshoulder angles (Mademlis et al., 2019). Although drone filming has been presented as a game-changer in the media industry (Adams, 2019), there is very little research on the subject (Table 1), and what exists focuses primarily on safety and ethics in relation to news production (Belair-Gagnon, Owen, \& Holton, 2017).

One of the first research studies conducted in the USA found that half of the 94 local television news directors interviewed were already using drones in the news, although moderately (Ferguson \& Greer, 2019). Its positive contribution has also been assessed by Turkish news agencies for its ability to record images in places that are difficult to access (Budak, 2019), sometimes replacing the use of eyewitnesses, who sometimes imply sound and visual manipulation of the event that diminishes the critical and informative role of the media (Spaziante, 2018). Recording images with drones requires knowledge of audiovisual language, so more and more drone pilots with journalistic goals work as television camera operators in Spain (Gallardo-Camacho \& Lavín, 2016).

The scientific literature also includes research into other technological applications that could be incorporated into audiovisual news, such as $360^{\circ}$ video or immersive journalism (Mañas-Viniegra, Veloso, \& SierraSánchez, 2020), yet there has been no focus on the integration of images filmed with drones as a way of capturing the attention of conventional media audiences, which in the case of television in Spain has experienced a drop in numbers (or coverage) of $4.04 \%$ since 2012, with 14-19 year olds and 20-24 year olds being the two groups with the lowest audience figures, at $79.6 \%$ and $78.4 \%$, respectively (AIMC, 2019).

The first research to compare the aerial recording of a drone with that of a tripod-mounted video camera focused on differences in the ability to observe the behaviour of school-aged children, with no significant differences detected (King, Bloomfield, Fischer, Dart, \& 
Table 1. Scientific literature on drone journalism.

\begin{tabular}{|c|c|}
\hline Authors & Research topics \\
\hline $\begin{array}{l}\text { Andrejevic and Burdon (2015); Ballout, Ghaddar, and Wehbi (2019); } \\
\text { Belair-Gagnon, Owen, and Holton (2017); Cavaliere, Loia, Saggese, } \\
\text { Senatore, and Vento (2019); Clothier, Greer, Greer, and Mehta (2015); } \\
\text { Fernández-Barrero, 2018; Holton, Lawson, and Love (2015); } \\
\text { Rule (2015); Sekander, Tabassum, and Hossain (2018); }\end{array}$ & $\begin{array}{l}\text { Advantages, barriers and opportunities } \\
\text { regarding the technology and use of drones } \\
\text { applied to journalism. }\end{array}$ \\
\hline $\begin{array}{l}\text { Adams (2019); Galvane et al. (2018); Mademlis et al. (2019); } \\
\text { Tham, Selem, and Ogulin (2017) }\end{array}$ & Contribution of drones to the media. \\
\hline Ferguson and Greer (2019); Gallardo-Camacho and Lavín (2016) & Use of drones for news purposes on television. \\
\hline Budak (2019) & Use of drones in news agencies. \\
\hline Cauchard, Zhai, Spadafora, and Landay (2016) & Human-drone interaction. \\
\hline King, Bloomfield, Fischer, Dart, and Radley (2020) & $\begin{array}{l}\text { Comparison of a recording made by a drone } \\
\text { with a recording made with a video camera } \\
\text { mounted on a tripod, though not for journalistic } \\
\text { purposes. }\end{array}$ \\
\hline
\end{tabular}

Radley, 2020). This issue, applied to the recording of news, is the focus of this research, which intends to offer an answer to this issue by means of neuromarketing techniques.

\section{Materials and Methods}

The overall objective of this research is to determine the differences in attention and intensity of the emotions produced in young Spanish university students when viewing a news item filmed with the technological support of a drone when compared to other conventional news items. The following specific objectives were established:

- Record the attention and emotion of the subjects toward the news filmed with drones.

- Determine the differences between the attention and emotion directed at the different audiovisual formats.

- Establish differences between the appearance, or non-appearance, of people in the filming of the news.

The research questions posed for the objectives above are as follows:

RQ 1: Is there a relation of dependence between the attention and emotion of young people toward news filmed with drones?

RQ 2: Are there any differences between a drone recording and a conventional news recording?

RQ 3: Is it the technology, or the recorded scene, that determines the difference?
The research techniques used have been fully consolidated (Morin, 2011) and are typical of neuromarketing, or applied neurocommunication (Cuesta-Cambra, Niño-González, \& Rodríguez-Terceño, 2017), as they allow for measurement of the subjects' cognitive processes based on the stimuli presented. Moreover, they incorporate the principles of neuroscience, psychology and economics (Madan, 2010). Specifically, eye tracking has been used to record the subjects' attention to stimuli, and galvanic skin response (GSR) was used to analyse emotional arousal. When simulating a natural viewing environment, priority is given to the use of non-intrusive equipment, with an ability to predict efficiency between $70 \%$ and $80 \%$ (Varan, Lang, Barwise, \& Bellman, 2015).

Eye tracking allows the subjects' visual attention to be recorded using biometric techniques that register eye movements toward the areas of interest (AOI) of the stimuli shown to the participating subjects. This technique separates the attention directed at the AOI from areas that are ignored, or that are simply browsed over while heading toward $\mathrm{AOI}$ to the subjects (Duchowski, 2013). In this way, the software records the AOI that capture the most attention and emotion, taking into account that the young audience has more ability to quickly focus their attention on the information in a stimulus that is relevant and of interest to them (Añaños-Carrasco, 2015). From the attention registered, the software generates heat maps in which it is possible to see visually where the attention is concentrated, as well as the different intensities depending on the colour, with the colour red being located in the centre of the heat map and representing the area with the most intense level of attention. In research in which people are asked to visualize stimuli, even though it is common for participants to register a higher level of attention compared to an unobserved environment, the fact that they do not know which stimuli 
are of interest to the researchers allows these investigators to analyse the differences between the stimuli.

Also known as electro dermal activity, GSR records the changes in electrical conductance of the skin from the phasic changes that occur in sympathetic neuronal activity. In this way, changes in emotional arousal are obtained, which influence the cognitive perception that the subjects have of the stimuli (Critchley, 2002).

Eye tracking and GSR techniques record the unconscious responses of subjects to visualized stimuli and partially indicate whether an influence on the audience is occurring through the analysis of cognitive and affective processing (Bornstein \& D'Agostino, 1992; Goodrich, 2011; Pieters, Warlop, \& Wedel, 2002). Recording these unconscious responses allows for the study of cognitive processing, as traditional research methods are limited by the difficulty subjects have in reporting their own perceptions, attitudes or behaviours (Ariely \& Berns, 2010).

Thirty subjects participated in this study on a random voluntary basis, and all of the subjects fulfilled the requirement of being university students between 18 and 23 years of age, which is the group closest to the application of technology to audiovisual media (CasillasAlvarado, Ramírez-Martinell, \& Ortega-Guerrero, 2016). Despite the fact that the incidental sample had been planned for 50 subjects, the health crisis of the Covid19 forced a halt to the fieldwork, which was carried out between January and February of 2020. The sample was taken from Madrid (Spain). The final sample size is valid for a neuromarketing study, as it fulfils the number of 15 to 50 subjects recommended by the scientific literature (Kerr-Gaffney, Harrison, \& Tcanturia, 2018).

Data collection was performed using a Gazepoint eye tracker GP3HD $150 \mathrm{~Hz}$ sampling rate, along with a GSR Gazepoint Biometrics system, integrating the analysis of the recorded data into the Gazepoint Analysis UX Edition v.5.3.0 software. The statistical use of the results was carried out using SPSS v. 25 software.

The stimuli presented to the subjects (randomly and interspersed with other stimuli) were two versions of the same 40-second audiovisual news item about France's decision to restrict access to Mont Blanc for unguided climbers. The first was a conventional news item published by Euronews, while the second version was interspersed with ad hoc images filmed with the technological support of a drone. The aerial images were recorded with a Mavic 2 Pro Zoom drone. The shots were captured at an altitude of over 4,000 meters, which involved heating the batteries to overcome the low air density and temperature of less than 5 degrees below 0 Celsius $\left(-5^{\circ} \mathrm{C}\right)$. The two stimuli analysed were intermixed with other news items, with a total duration of 15 minutes. The AOI (Table 2) were defined, which allowed for a comparison to be made between the images filmed with a drone and those taken with conventional means in a place of difficult access, such as Mont Blanc.

The level of attention recorded by eye tracking, and the peaks of emotional arousal recorded by GSR when visualizing the stimuli, were considered to be dependent variables. As an independent variable, the gender of the participants was taken into account, since both the age range and socio-cultural profile were similar in all subjects. An initial qualitative evaluation of the content was made using heat maps of attention toward the stimuli, combined with a conscious statement by the subjects with regard to the positive, negative or neutral emotion shown toward the AOI, for which the technological support offered by GSR Gazepoint Biometrics was used. Subsequently, a quantitative analysis of attention was carried out based on the seconds that passed from the appearance of the stimulus until the first fixation, or time from fixation (TFF), the number of eye fixations, or fixa-

Table 2. Areas of interest (AOI) of the stimuli.

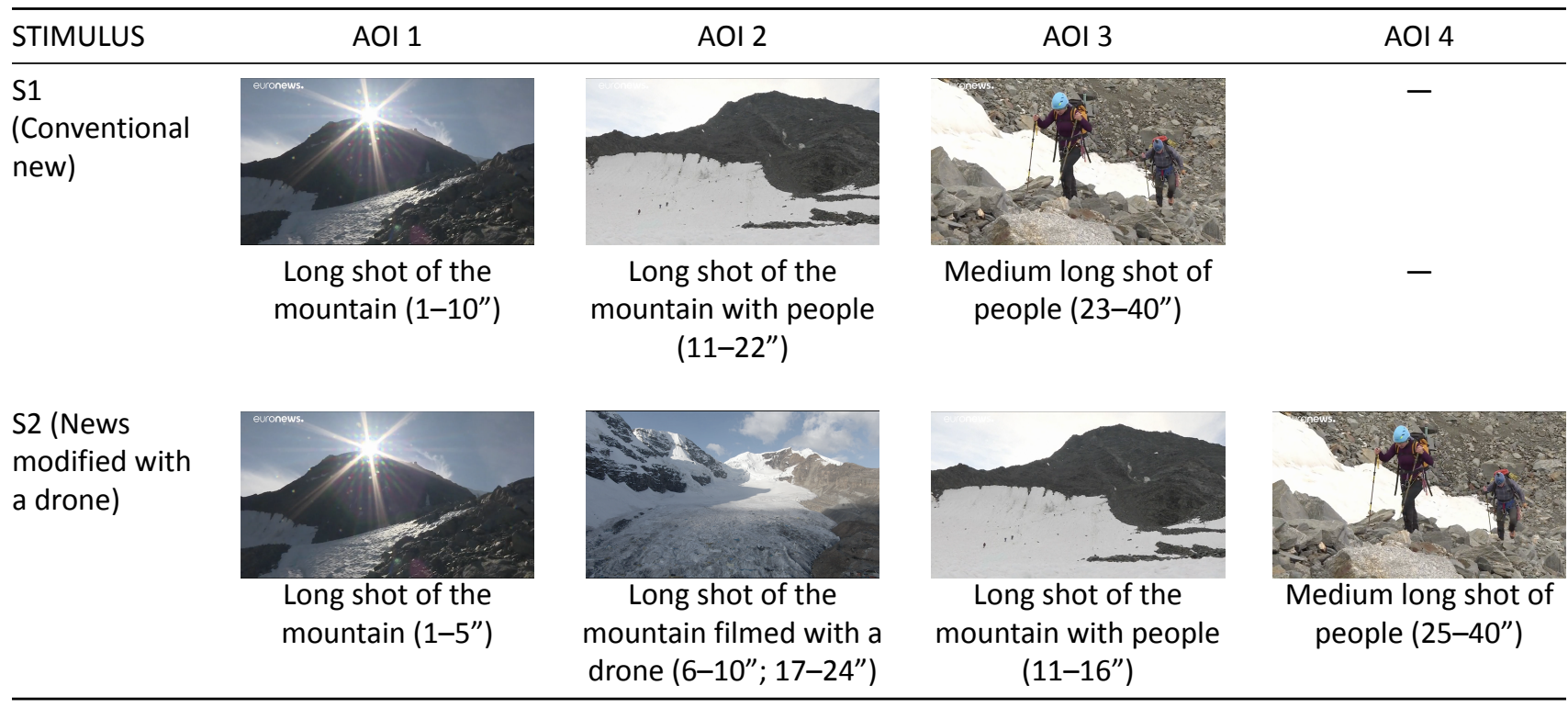

Sources: Euronews (2018) and Volandovoy.tv. 
tion count (FC), and the number of total seconds of attention to each area of interest, or total fixation duration (TFD). A quantitative analysis of emotional arousal was carried out using the GSR peaks that arose from each minimum-maximum pair from the beginning of the emotional activation.

This research was approved by the Research Ethics Committee (CEI) of the Department of Applied Communication Studies of the School of Media and Communication, Complutense University of Madrid. Participants signed the consent form, which included voluntary participation and their anonymous contribution, in accordance with the Declaration of Helsinki.

\section{Results}

\subsection{Qualitative Content Analysis}

The qualitative content analysis of the stimuli carried out using heat maps (Table 3 ) had already indicated similar behaviour among the young audience in the presence of different $\mathrm{AOI}$ and their visual elements. These visual elements stand out in all cases, except with the images filmed by drones, in which case the attention of the young audience is focused on one or more elements present in the scene, whether due to spectacular panoramas, luminosity, movement or colour.

The long shot of the mountain (S1-AOI 1; S2-AOI 1) recorded similar levels of attention in both stimuli, which was focused on the natural lighting caused by the sunset on the mountain peak. In the first stimulus, which lasted longer, the secondary viewing surface was larger and more extended.

In the second long shot of the mountain (S1-AOI 2; S2-AOI 3), the attention is focused on people moving within the static shot. In the first stimulus, as a consequence of longer duration on the area of interest, the attention of both groups of people is extended to the path going up the mountain.

With regard to the medium long shot with climbers in motion (S1-AOI 3; S1-AOI 4), in the first sequence of both stimuli, attention is focused on the two climbers in motion, the tents with their striking colour, and the Mont Blanc information poster, also in bright colours. In the second sequence, attention is also drawn to the two climbers in motion, although in this case most of the attention is focused on the climber in brightly-coloured clothing.

The exception to this pattern of attention behaviour is in the long shot of the mountain filmed with a drone, composed of two separate sequences in the timeline of the stimulus. In both, the attention is distributed horizontally along the entire mountain, accompanying the movement of the camera.

\subsection{Quantitative Analysis of Attention}

In the first comprehensive analysis of attention registered by the subjects, the shot of the mountain filmed with a drone (S2-AOI 2) was the $\mathrm{AOI}$ in which the attention was focused by the highest percentage of participants (93.33\%), although this comprehensive datum is always high in this type of study in which subjects are asked to visualize stimuli.

The analysis of results, which was carried out using the medians of TFF, TFD and FC measurements described in the section entitled 'Materials and Methods,' did not identify significant differences based on the gender of participants, and this question has been omitted for that reason.

In all AOI, both stimuli recorded a median elapsed time of less than a tenth of a second from the appearance of the area of interest to the first fixation (TFF), so the content did not create any distractions for the participants, as the attention was fast in all AOI. The significant differences ( $p=<0.001$ ) are a consequence of the diverse moments when each area of interest appeared in the news.

In stimulus $1, \mathrm{AOI} 2$ had the longest total duration of attention (TFD) with regard to total screen time of the AOI (91.02\%), compared to $89.42 \%$ for $\mathrm{AOI} 3$ and $89.13 \%$ for AOI 1. Therefore, attention recorded by visual elements that move within a static shot is somewhat higher, despite the fact that there is little difference between the three AOI. In the same way, the number of fixations (FC) was significantly higher in the $\mathrm{AOI}$ of longer duration, but in relative terms there were hardly any differences.

In stimulus 2, the total duration of attention (TFD) was also very similar among all $\mathrm{AOI}$ in relative terms according to the duration of each stimulus. Thus, all of them reached an attention duration of between $90.32 \%$ and $91.73 \%$ of the total. In absolute terms, close-ups of climbers in motion and images recorded with drones were the $\mathrm{AOI}$ with the longest total duration of attention. However, the number of eye fixations (FC) was significantly higher in images filmed with drones ( $F C=35)$, both in absolute and relative terms for the duration of the stimuli.

After analysing these absolute results, similar AOI of both stimuli were analysed in pairs, applying a weighting factor to the results according to the different duration lengths of each $A O I$. Thus, both the total duration of attention (TFD) and the total number of eye fixations (FC) toward the long shot of the mountain in both stimuli was very similar, showing no significant differences (TFD $=4.751$ vs. $4.885 ; p=0.311 ; F C=11$ vs. 10 ; $p=0.094)$, which is consistent, due to the fact that the same shot was used in both stimuli.

Real-time analysis (non-cumulative results) of the heat maps (Table 4) shows that the longer total duration of the scene in stimulus 1, recorded with a camera on a tripod, initially allows for a larger vertical viewing area, although the main focus of attention is then concentrated on the sunrise, which is the same for both stimuli.

Moreover, a comparison between the total duration of attention in both stimuli show significant differences (TFD $=4.975$ vs. $5.014 ; p=0.328$ ), although the number 


\section{COGITATIO}

Table 3. Heat maps of the stimuli.

AOI 1

AOI 2
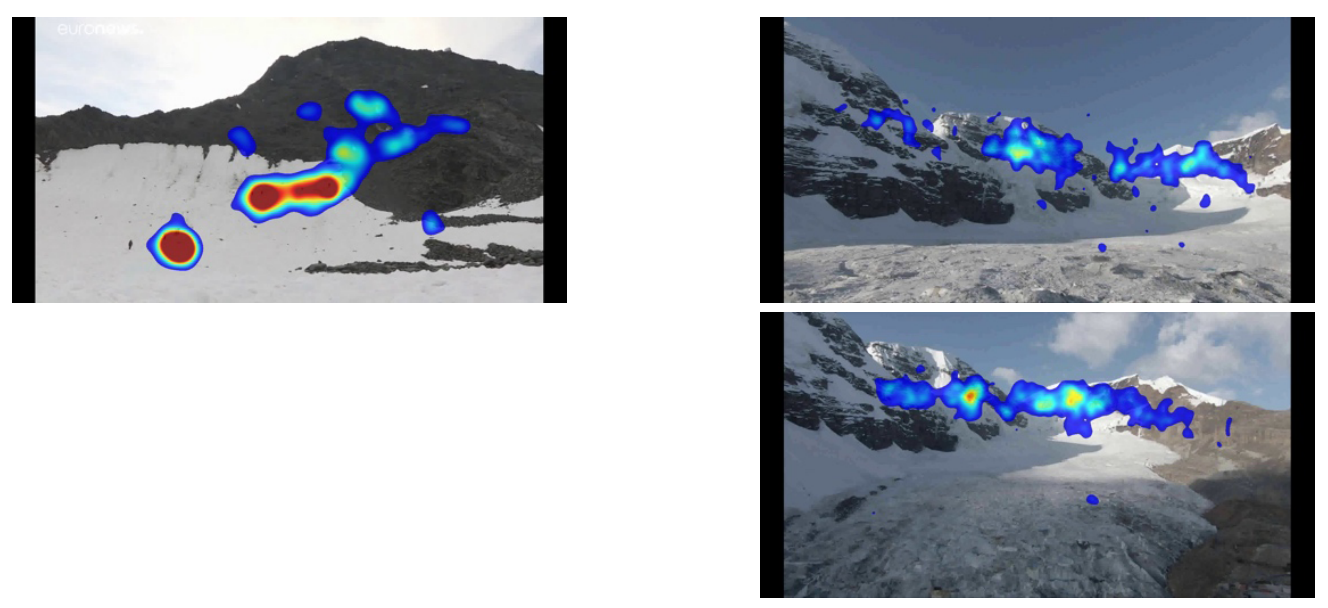

$\mathrm{AOI} 3$
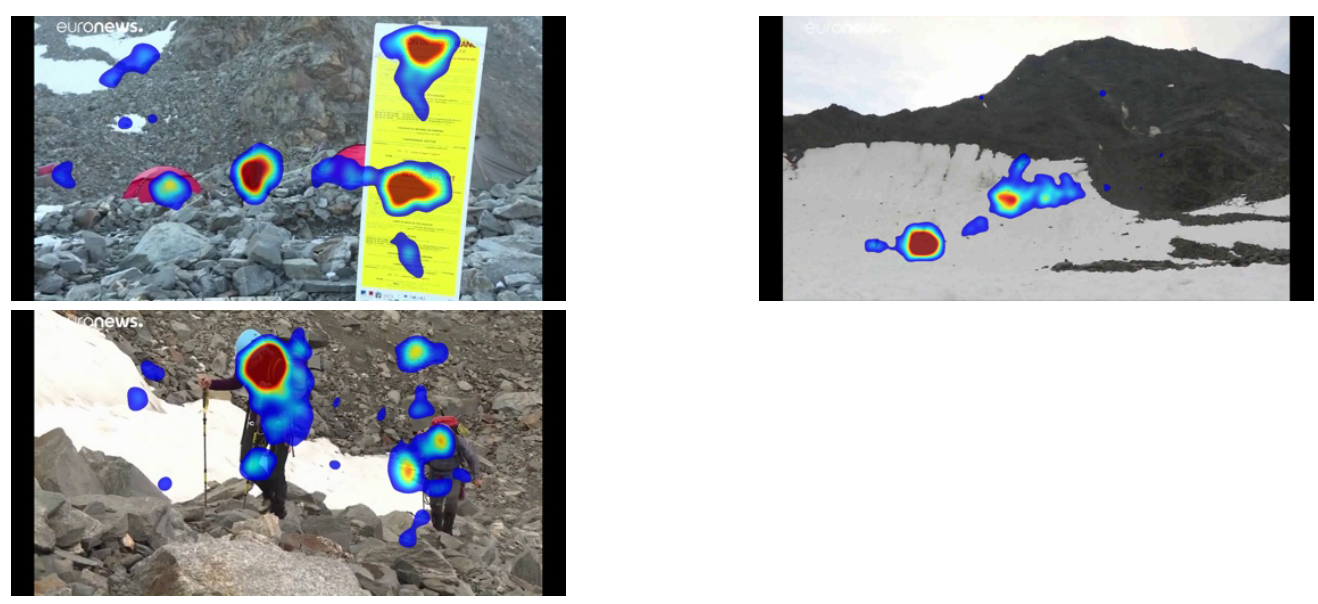

AOI 4
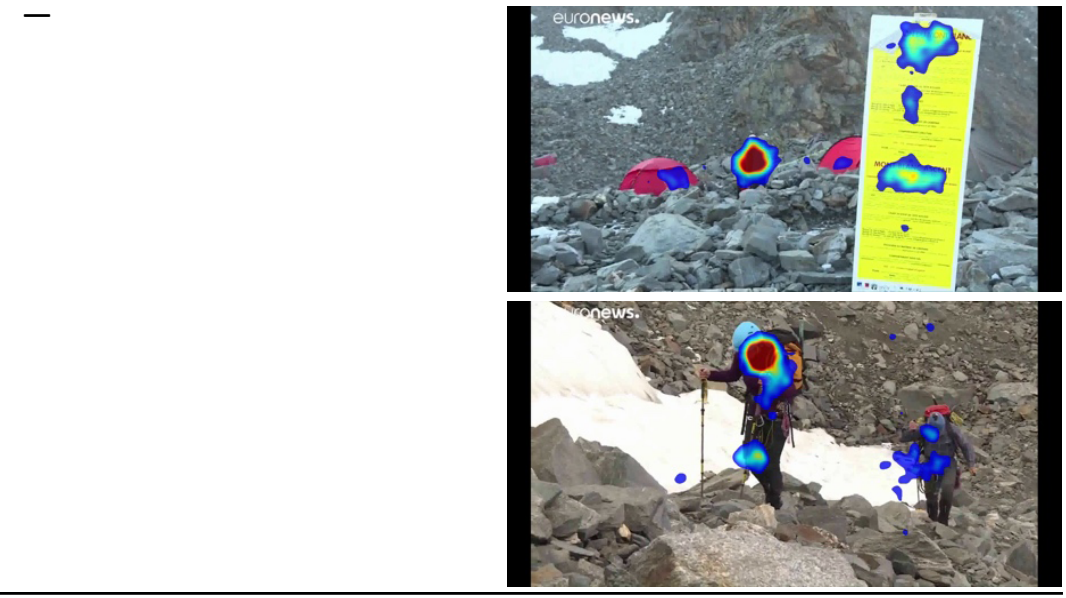

Source: Euronews (2018). 
Table 4. Heat maps of the stimuli.

\begin{tabular}{llll}
\hline AOI & S1 \\
\hline AOI 1 & euronews. & S1 \\
\hline
\end{tabular}

Source: Euronews (2018).

of eye fixations ( $F C=11$ vs. $13 ; p=0.042$ ) was significantly higher in the case of the stimulus that included the scene filmed with the drone.

In the real-time heat maps of stimulus 1 , in which the scene is twice as long as in stimulus 2 (Table 5), it became clear that the attention was focused more intensely on the moving climbers, first on the group in the foreground, after which the attention moved toward the other secondary groups of climbers before continuing its visual movement toward the route they were likely to take to climb Mont Blanc. Precisely due to the shorter duration of the scene in stimulus 2, the attention was concentrated on the groups of climbers, and only on the beginning of that particular route to ascend Mont Blanc.

As for the medium long shot with the climbers in motion, the attention was also similar in both stimuli, with no significant differences in the total duration of attention and the number of eye fixations (TFD $=14.271$ vs. 14.546, $p=0.229 ; \mathrm{FC}=35$ vs. $34, p=0.895$ ).

The real-time heat maps showed (in Table 6) that stimulus 1, which was of longer duration, first captured the focused attention of the moving climbers, and then the attention was distributed among the climbers and the elements that stood out with intense colour, especially the Mont Blanc information poster. In stimulus 2, in which the scene has a shorter duration, the evolution of the heat maps was the same, although it was observed that the main element was the people in motion and not the features with intense colours, because when the viewing time is shorter, the subjects have to prioritise the elements that most capture their attention.

The real-time heat maps of the second part of the same scene (Table 7) confirmed that attention was concentrated on the main element of the scene with movement, which was the first climber, and then the attention was shared with similar intensity between both climbers, and finally focused on the second climber, with insignificant attention placed on the natural environment when the people in movement appeared, as was seen in other AOI.

Results of the paired analysis of identical AOI in both stimuli suggest that the inclusion of a new scene filmed with a drone has no influence on the attention paid to the rest of the shots included in the original stimulus. Therefore, at this point it is necessary to make a specific comparison related to the long shot of the mountain filmed with a drone that was introduced in stimulus 2, which modified the original Euronews broadcast. Thus, by comparing the long shot of the mountain with the long shot filmed with the drone of stimulus 2 , there was no significant difference regarding the total duration of attention (TFD $=4.885$ vs. $4.815 ; p=0.166$ ), but there were differences in the number of eye fixations, which were much higher in the case of the long shot recorded with the drone ( $F C=10$ vs. $14 ; p=<0.001)$.

Real-time analysis of the heat maps shows that unlike the long shot of the mountain recorded with a tripod camera, the recording made with the drone (Table 8)

Table 5. Heat maps of the stimuli.

\begin{tabular}{|c|c|c|}
\hline AOI & S1 & S1 \\
\hline $\mathrm{AOI} 2$ & & \\
\hline
\end{tabular}

Source: Euronews (2018). 


\section{COGITATIO}

Table 6. Heat maps of the stimuli.

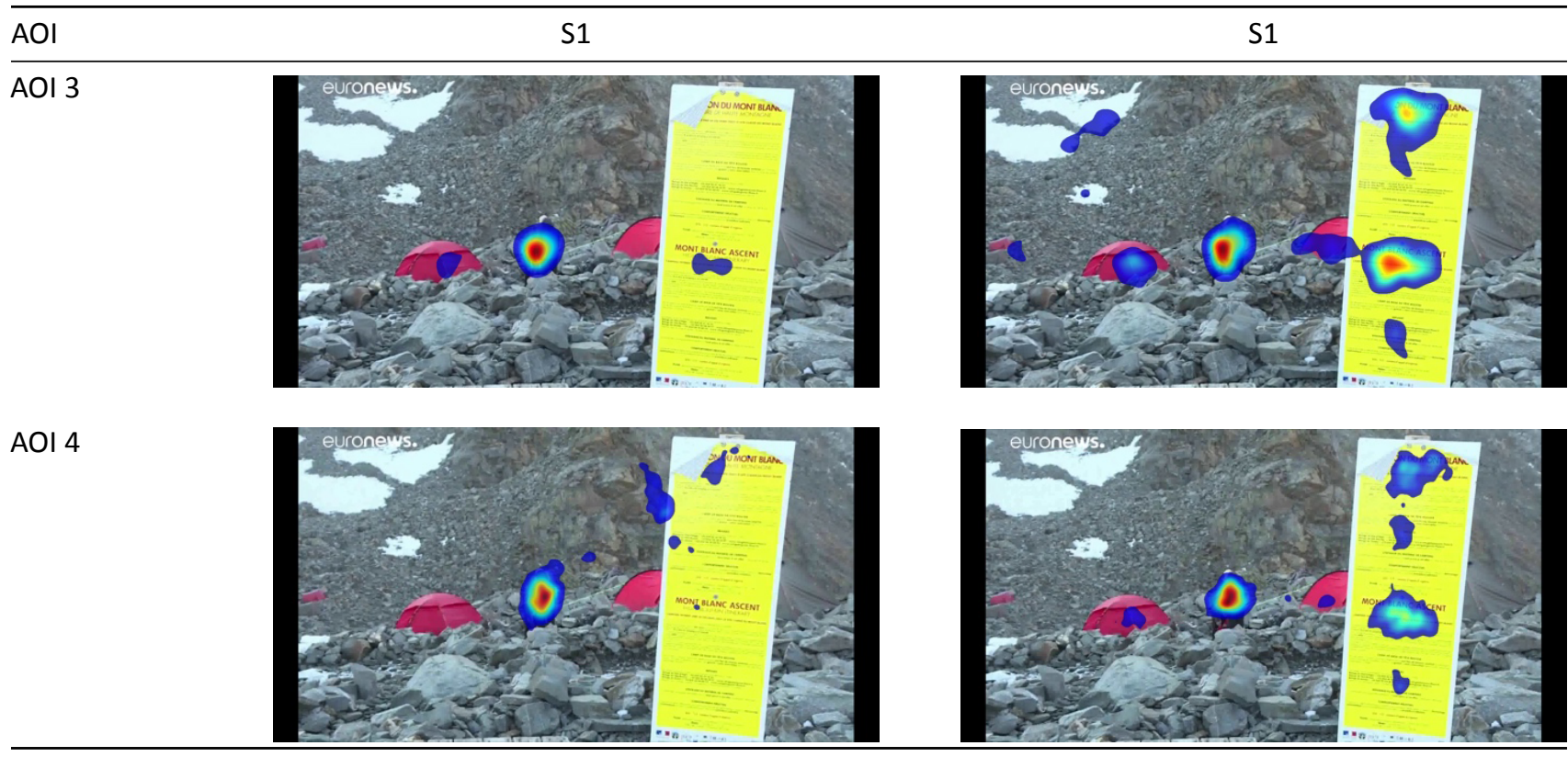

Source: Euronews (2018).

shifts from an initial focus on the mountain peak to a horizontal distribution a few seconds later, as opposed to the vertical distribution recorded with a tripod camera.

Already in stimulus 2, the young audience had the same reaction when comparing the long shot of the mountain filmed with the drone and the long shot of the mountain with people. There were no significant differences in the total duration of attention (TFD $=4.937$ vs. 5.014, $p=0.086$ ), but there were differences in the number of eye fixations, which were significantly higher in the case of the sequence filmed with the drone ( $F C=15$ vs. $13 ; p=0.002$ ).

Finally, a comparison made between the shot filmed with a drone and the medium long shot of the climbers also showed no significant differences between the total duration of attention of the two stimuli (TFD $=11.716 \mathrm{vs}$. 11.823; $p=0.225$ ), but there was a much higher number of eye fixations, which was statistically significant, in the case of the long shot of the mountain filmed with the drone (FC $=35$ vs. $28 ; p=<0.001$ ).

Table 7. Heat maps of the stimuli.

\begin{tabular}{|c|c|c|c|}
\hline $\mathrm{AOI}$ & S2 & $\mathrm{S} 2$ & $\mathrm{~S} 2$ \\
\hline $\mathrm{AOI}$ & & & \\
\hline
\end{tabular}

Source: Euronews (2018).

Table 8. Heat maps of the stimuli.

\begin{tabular}{|c|c|c|c|}
\hline $\mathrm{AOI}$ & S2 & S2 & S2 \\
\hline $\mathrm{AOI}$ & & & \\
\hline
\end{tabular}

Source: Euronews (2018) 


\subsection{Emotional Intensity Analysis}

The subjects' conscious responses remained neutral in all $\mathrm{AOI}$, except in the long shot of the mountain (S1-AOI 1; S2-AOI 1) and the long shot of the mountain filmed with the drone (S2-AOI 2), in which case they expressed a positive response to the stimulus. In terms of emotional intensity from the participants' unconscious responses, provided by GSR data (Figure 1), it remained constant during the news broadcast, with slight growth as the narrative progressed. However, there are two GSR peaks that coincide with the long shot of the mountain in which the sunset stands out, with $510.75 \mathrm{kOhm}$. (S2-AOI 1) and $498.79 \mathrm{kOhm}$. (S1-AOI 1), as well as the long shot of the mountain filmed with the drone (S2-AOI 2), with a peak GSR of $644.54 \mathrm{kOhm}$. (S2-AOI 2), the maximum recorded in both stimuli.

\section{Discussion}

The usefulness of drones in the audiovisual production of news that takes place in locations that are difficult to access or involve risks for people can be summarized as the recording of high-resolution images at a low cost, capable of having its own tailored storytelling developed for the purpose of providing different points of view to the audience. In order carry out this task, pilots must be trained professionals who need to be officially licenced by the appropriate administration, but they must also be specialists in audiovisual communication. While the younger audience continues to stay informed about topics in which they are interested, they are doing so less with conventional media and increasingly with digital media, the latter of which is more innovative in aesthetics and narratives, with the result being that drones can contribute to revitalizing conventional media.
Within each area of interest and each shot, the subjects' attention was focused on the most spectacular visual elements, which can be grouped according to their panorama, luminosity, movement or colour.

The highest percentage of the subjects' attention was focused on the images filmed with drones, and unlike the rest of the shots, it was distributed throughout the entire image, which confirms the effectiveness of drones for panoramic shots, precisely the easiest to obtain in places of difficult access.

Although the total duration of attention to the AOI repeated in both stimuli did not register significant differences, nor did the shots filmed with the drone, the latter showed significantly more eye fixations, as well as the highest GSR peak of all, which concurred with the subjects' conscious statement of experiencing positive emotions during their viewing. However, inclusion of the scene filmed with the drone in stimulus 2 did not result in higher emotional arousal with regard to the entire stimulus to a significant degree, except in the two specific scenes in which the images were recorded with a drone.

In the long shot taken by the drone, the focus of attention was distributed throughout the entire shot, while in the other long shots the focus of the view depended on the internal movement within the shot. This may suggest that shots filmed with drones have greater focus throughout the entire shot, thereby uncovering more allencompassing aspects, while long shots taken at ground level have an impact on the precise location of features within the shot. Therefore, shots filmed with drones offer much more detail and place greater attention on the shot itself, both in viewing time and in the viewing space (inside the shot).

The factor involving the spectacular aspect of the shots analysed is an element that must be taken into

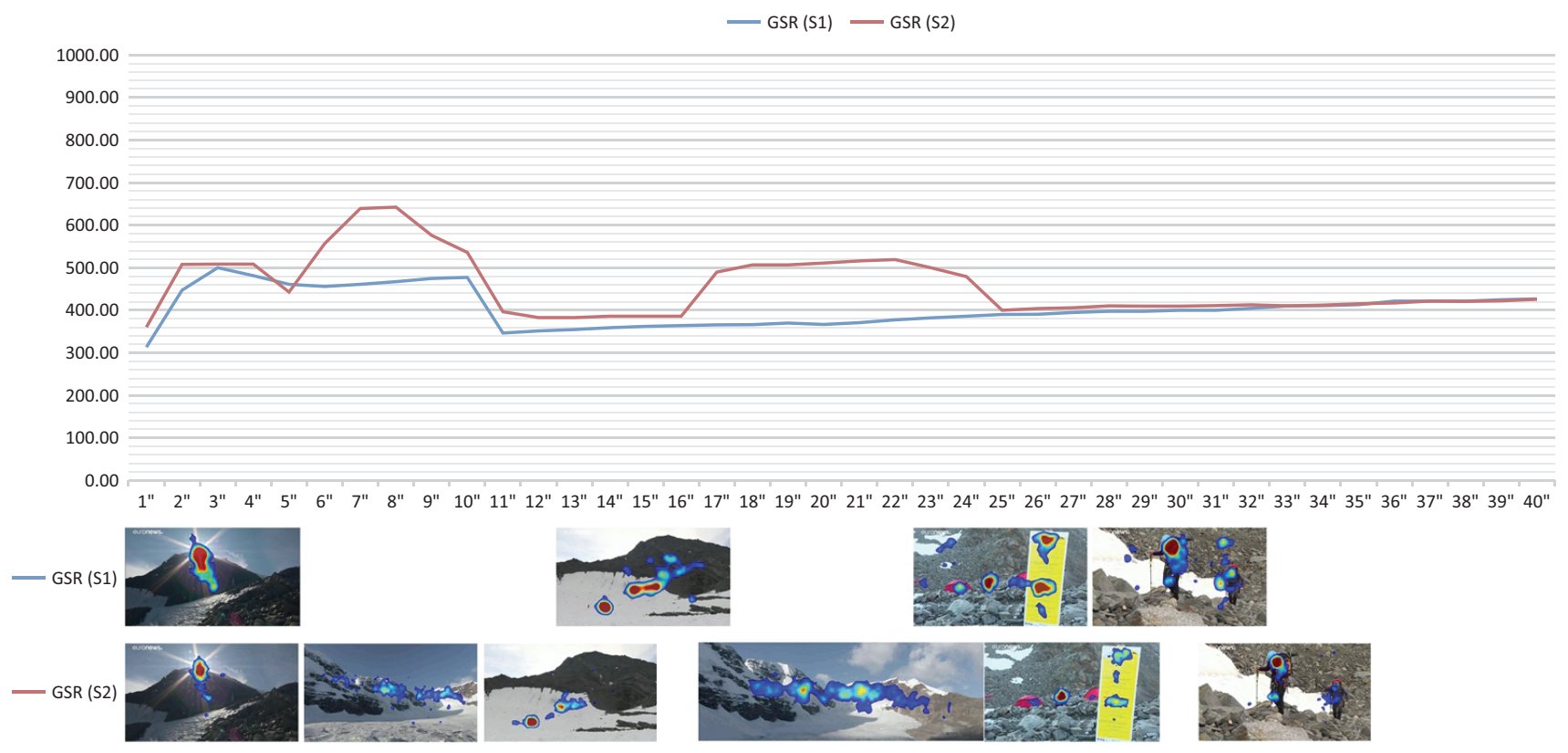

Figure 1. GSR peaks of the stimuli. Source: Euronews (2018). 
account in order to fully understand the objective of this research. The use of drones necessarily requires open spaces to be able to comply with all of the regulatory restrictions their use implies. Therefore, not all topics - in this case news - can be addressed with shots made with drones. The variables of attention and emotion are altered to some extent by this regulatory situation. This fact, together with the extensive visual culture of the spectators, especially the youngest, among whom are included the subjects used for this study, directly influences and determines the spectacular aspect factor that seems to be mandatory when dealing with certain subjects.

The function of the producer or journalist, who selects the images used to visually describe a news item, as was the case herein, is to select a point of view on which to build the narrative. The position of the camera is the focal point from which the viewer contemplates a scene. Therefore, in the shots taken with the camera, it is natural for the area of interest to be focused on those elements within the shot that stand out, either because of their luminosity or their movement. It is important to note that the human eye is especially sensitive to brightness (not so much to colour) as well as internal movement within its field of vision. In fact, this is the foundation on which the entire digital coding of the MPEG system for television has been built: First, the brightness is analysed, after which only those elements that change within a structured pattern of pixel grids are examined.

The use of drones implies a new point of view, which in the end is something that cannot possibly occur in a natural way for the spectator. It is not possible for a human being to contemplate for him or herself the visual space as shown by a drone. In addition, this means that the capacity for discovery is implied in the shot itself. The spectator explores this new reality and tries to discover the main essence of all the elements that make up the shot. Therefore, the range of AOI is more horizontal and includes a larger area of exploration, altering both attention and emotion at the same time and the same levels. The use of drones broadens and helps to rediscover the patterns on which the perception of reality that the human brain created from more or less standardized points of view had been built. In this case, we see the mountain and the activity described in the shots as a pattern or image already established in our brain, though with different actors. The recording made by drones is new to the visual imaginary on which reality has been built, and thereby forces the audience to explore it to a greater extent and with a higher degree of attention, while at the same time altering it emotionally on nearly identical levels, according to the data obtained.

Drones alter the point of view and add new perspectives on which the reality proceeding from the images is built. The data reflected in the AOI show the influence of this new perspective. Although the recording technology is similar to that of conventional cameras, the quality of the images obtained influences their perception. Higher resolution cameras, which can attain a greater level of detail in the captured image, allow a higher level of exploration of all parts of the image. Therefore, drone cameras have high definition technology to support this new area of visual exploration regarding the resolution detail of the image. As such, it is clear that as the level of resolution increases, the ability to influence attention is greater, and consequently, emotional levels as well, if we consider the data obtained in this research.

These results confirm the fact that the incorporation of technology in the audiovisual production of news has already taken place (Marcos-Recio, Edo-Bolós, \& Parra-Valcarce, 2018), and provides alternative views of events that raise the public's awareness (Sacco, Gorin, \& Schiau, 2018), due to the fact that they have a narrative experience that improves understanding and empathy toward the key players in the news (Ruiz-Collantes, 2008). In addition, all of these issues improve the dissemination of content thanks to the virality of social networks (Sundar, Kang, \& Oprean, 2017). Moreover, the idea that filming with drones provides images for the context of the news rather than for informational content has also been reinforced (Adams, 2019), as well as the importance of using wider visual fields (Cummings \& Bailenson, 2016), and the fact that drones are able to capture visually appealing images of destinations that generate attention (Stankov, Kennell, Morrison, \& Vujicic, 2019).

In spite of this situation, drones are not included as emerging technologies in journalism or communication degrees in Spanish Universities, despite the fact that big data, photography $/ 360^{\circ}$ video, cloud computing, augmented/virtual reality, the 'Internet of Things,' artificial intelligence, and connected television are already present, although the sum of these represents only $14.04 \%$ of the total number of technology subjects (Sierra-Sánchez, Liberal-Ormaechea, \& Mañas-Viniegra, 2020). However, universities in the USA are beginning to create specific courses on drones (Chapa, 2013).

\section{Conclusions}

Emotional journalism transforms facts into experiences with the support of audiovisual technology, narratives, and the conversion of news into news stories. Drones can be an element that brings new points of view to this emotional journalism. The digitisation of the image has modified the narrative structure by allowing the message to be cloned, and with it, the viral use of such messages according to specific interests. The overall aim is to influence the attention, and above all the emotion, of the message's receiver.

Digitisation has also ushered in a new way of approaching recorded reality thanks to greater definition of inner detail. Moreover, this new achievement influences emotion and attention as it allows us to rediscover a filmed object from a more comprehensive perspective. The appearance of drones adds another important factor to the way in which reality is re-recorded: points of view 
that are impossible for human beings. Furthermore, this is the place where we must set new standards of filming that will help to optimize the use of drones as a tool at the service of the visual narrative.

Either due to the characteristics of the area filmed and/or the events recorded, or considering both variables at once, if one contemplates open spaces and the spectacular nature of the filming, these factors should serve as a basis for choosing this tool in order to explore new ways of creating emotion and attention in the spectator.

In the specific case analysed in this research, the premise of the spectacular aspect of the area filmed has been achieved, as a foundation from which to stimulate the viewer's attention and emotion. The data verify their correlation and usefulness in reinforcing the levels of visual exploration of the image shown.

Scenes recorded with a drone activate emotion more intensely than they activate attention (RQ 1), and they provide more spectacular panoramic images when it comes to natural landscapes (RQ 2), which may explain why attention is more distributed in the horizontal shot and not focalised, as in the natural landscapes recorded using a static shot with a camera on a tripod (RQ 3).

These results can be used to help understand the superiority of implementing a tool such as a drone to 'hook' the viewer on the image shown. The massive number of images emitted and visualized in the digital society through all kinds of platforms and social networks is resulting in lower levels of interest, as well as less motivation to delve deeper into the comprehension and stimulation of such images by the public. The use of drones allows for the exploration of new kinds of loyalty to the image based on quality and new points of view. In order to achieve these objectives to a high degree of excellence, it is necessary to specify appropriate training that would allow for an examination of all of these new channels.

\subsection{Management Implications}

The implications for management would be to increase the use of drone footage in news stories that require the viewing of large areas, or those that are difficult to access on foot, in order to better understand the scope of the news as well as to offer a type of immersion in the place where news is occurring. From the point of view of universities, they should include subjects that apply the technology and narratives of drones to the curricula of journalism as well as audiovisual communication and advertising, in order for students to obtain the necessary professional skills.

\subsection{Limitations and Future Lines of Research}

One of the main shortcomings of this research is the nonrepresentativeness of the sample. Even though the size is adequate for a neuromarketing study, it is limited to Spanish university students. In addition, the lack of fund- ing for this research has prevented the author from having access to AFFDEX analysis of facial expression of emotions, which has been replaced by recording the emotional intensity and conscious reporting of the types of emotions experienced by the participants. The difficulty of simulating a real environment in a neuromarketing laboratory should also be noted (Mileti, Guido, \& Prete, 2016). However, this issue offers the advantage of delving deeper into causes by combining them with qualitative research (Berns, Capra, Moore, \& Noussair, 2010). As a result, future lines of research should involve carrying out cross-cultural investigation to establish sociocultural differences between diverse geographical areas (Alsaleh, Elliott, Fu, \& Thakur, 2019), analysis of facial coding when funding is obtained, comparison with other scenes recorded using drones, such as images of disasters, as well as the development of tailored storytelling for content based on aerial images of drones, according to whether their use would be for journalistic, audiovisual or advertising-related purposes.

\section{Acknowledgments}

The authors would like to thank Volandovoy.tv and Yeray Martín Perdomo for providing the aerial images recorded with a drone.

\section{Conflict of Interests}

The authors declare no conflict of interests.

\section{References}

Adams, C. (2019). Tinker, tailor, soldier, thief: An investigation into the role of drones in journalism. Digital Journalism, 7(5), 658-677. https://doi.org/10.1080/ 21670811.2018.1533789

AIMC. (2019). Estudio general de medios (EGM), 2019, 3a ola [general media study (EGM), 2019, 3rd. stage]. AIMC. Retrieved from http://reporting.aimc.es/ index.html\#/main/cockpit

Alsaleh, D. A., Elliott, M. T., Fu, F. Q., \& Thakur, R. (2019). Cross-cultural differences in the adoption of social media. Journal of Research in Interactive Marketing, 13(1), 119-140. https://doi.org/10.1108/JRIM10-2017-0092

Añaños-Carrasco, E. (2015). EyeTracker technology in elderly people: How integrated television content is paid attention to and processed. Comunicar, 23(45), 75-83. https://doi.org/10.3916/C45-2015-08

Andrejevic, M., \& Burdon, M. (2015). Defining the sensor society. Television \& New Media, 16(1), 19-36. https://doi.org/10.1177/1527476414541552

Ariely, D., \& Berns, G. S. (2010). Neuromarketing: The hope and hype of neuroimaging in business. Nature Reviews Neuroscience, 11, 284-292. https://doi.org/ $10.1038 / \mathrm{nrn} 2795$

Ballout, A., Ghaddar, A., \& Wehbi, H. (2019). MMVS/COE: 
Mobile multi-view video streaming with constant order encoding. Multimedia Tools and Applications, 78(8), 10753-10772. https://doi.org/10.1007/ s11042-018-6564-6

Beckett, C., \& Deuze, M. (2016). On the role of emotion in the future of journalism. Social Media + Society, 2(3). https://doi.org/10.1177/2056305116662395

Belair-Gagnon, V., Owen, T., \& Holton, A. E. (2017). Unmaned aerial vehicles and journalistic disruption. Perspectives of early professional adopters. Digital Journalism, 5(10), 1226-1239. https://doi.org/10.1080/ 21670811.2017.1279019

Berns, G. S., Capra, C. M., Moore, S., \& Noussair, C. (2010). Neural mechanisms of the influence of popularity on adolescent ratings of music. Neurolmage, 49, 2687-2696. https://doi.org/10.1016/ j.neuroimage.2009.10.070

Bornstein, R. F., \& D'Agostino, P. R. (1992). Stimulus recognition and the mere exposure effect. Journal of Personality and Social Psychology, 63(4), 545-552. https://doi.org/10.1037/0022-3514.63.4.545

Budak, E. (2019). The effects of technological developments on journalism practices: Drone journalism in Turkey. Turkiye Iletisim Arastirmalari Dergisi, 33, 119-130. https://doi.org/10.17829/turcom.510266

Caple, H., \& Bednarek, M. (2016). Rethinking news values: What a discursive approach can tell us about the construction of news discourse and news photography. Journalism, 17(4), 435-455. https://doi.org/ $10.1177 / 1464884914568078$

Casillas-Alvarado, M. A., Ramírez-Martinell, A., \& OrtegaGuerrero, J. C. (2016). Afinidad tecnológica de los estudiantes universitarios [Technological affinities of university students]. Innovación Educativa, 16(70), 151-175. Retrieved from https://www.uv.mx/ personal/mcasillas/files/2016/05/IE-70-8.pdf

Cauchard, J. R., Zhai, K. Y., Spadafora, M., \& Landay, J. A. (2016). Emotion encoding in human-drone interaction. In C. Bartneck, Y. Nagai, A. Paiva, \& S. Savanovic (Eds.), HRI '16: The Eleventh ACM/IEEE International Conference on Human Robot Interaction (pp. 263-270). Piscataway, NJ: IEEE Press.

Cavaliere, D., Loia, V., Saggese, A., Senatore, S., \& Vento, M. (2019). A human-like description of scene events for a proper UAV-based video content analysis. Knowledge-Based Systems, 178, 163-175. https:// doi.org/10.1016/j.knosys.2019.04.026

Chapa, L. (2013). Drone journalism begins slow take off. News Media and the Law, 37(2), 9-13. Retrieved from https://www.rcfp.org/wp-content/uploads/ 2019/01/Spring_2013.pdf

Clothier, R. A., Greer, D. A., Greer, D. G., \& Mehta, A. M. (2015). Risk perception and the public acceptance of drones. Risk Analysis, 35(6), 1167-1183. https:// doi.org/10.1111/risa.12330

Coddington, M. (2015). Clarifying Journalism's quantitative turn. A typology for evaluating data journalism, computational journalism, and computer-assisted re- porting. Digital Journalism, 3(3), 331-348. https:// doi.org/10.1080/21670811.2014.976400

Critchley, H. D. (2002). Electrodermal responses: What happens in the brain. Neuroscientist, 8(2), 132-142. https://doi.org/10.1177/107385840200800209

Cuesta-Cambra, U., Niño-González, J. I., \& RodríguezTerceño, J. (2017). The cognitive processing of an educational app with EEG and eye tracking. Comunicar, 52(3), 41-50. https://doi.org/10.3916/C52-2017-04

Cummings, J. J., \& Bailenson, J. N. (2016). How immersive is enough? A meta-analysis of the effect of immersive technology on user presence. Media Psychology, 19(2), 272-309. https://doi.org/10.1080/15213269. 2015.1015740

Duchowski, A. (2013). Eye tracking methodology: Theory and practice. Berlin: Springer.

Euronews. (2018, September 5). Francia restringirá las ascensiones al Mont Blanc [France will restrict access to Mont-Blanc]. Retrieved from https://youtu. be/DzpWWPm458E

Ferguson, D. A., \& Greer, C. F. (2019). Assessing the diffusion of drones in local television news. Electronic News, 13(1), 23-33. https://doi.org/10.1177/ 1931243119829430

Fernández-Barrero, M. A. (2018). Periodismo y drones. Retos y oportunidades del uso de drones para la narración informativa en España [Journalism and drones. Challenges and opportunities of the use of drones in news production]. Doxa Comunicación, 26, 35-38. https://doi.org/10.31921/doxacom.n26a2

Gallardo-Camacho, J., \& Lavín, E. (2016). Uso de drones con fines informativos en empresas de televisión en España [Use of drones for informative purposes in television companies in Spain]. El Profesional de la Información, 25(2), 217-225. https://doi.org/10.3145/ epi.2016.mar.08

Galvane, Q., Lino, C., Christie, M., Fleureau, J., Servant, F., Tariolle, F. L., \& Guillotel, P. (2018). Quadrotor drones equipped with high-quality cameras. ACM Transactions on Graphics, 37(3). https://doi.org/ 10.1145/3181975

Goodrich, K. (2011). Anarchy of effects? Exploring attention to online advertising and multiple outcomes. Psychology \& Marketing, 28(4), 417-440. https://doi. org/10.1002/mar.20371

Harcup, T., \& O'Neill, D. (2017). What is news? News values revisited (again). Journalism Studies, 18(12), 1470-1488. https://doi.org/10.1080/ 1461670X.2016.1150193

Holton, A. E., Lawson, S., \& Love, C. (2015). Unmaned aerial vehicles: Opportunities, barriers, and the future of 'drone journalism.' Journalism Practice, 9(5), 634-650. https://doi.org/10.1080/17512786. 2014.980596

Huxford, J. E., \& Hopper, K. M. (2020). Reporting with emotion: A comparison of journalists' engagement in emotional labour across media types. Journal of Applied Journalism \& Media Studies, 9(1), 39-60. 
https://doi.org/10.1386/ajms_00010_1

Kerr-Gaffney, J., Harrison, A., \& Tcanturia, K. (2018). Eyetracking research in eating disorders: A systematic review. International Journal of Eating Disorders, 52(1), 3-27. https://doi.org/10.1002/eat.22998

King, H. C., Bloomfield, B., Fischer, A. J., Dart, E., \& Radley, K. (2020). A comparison of digital observations of students from video cameras and aerial drones. Journal of Educational and Psychological Consultation. Advance online publication. https://doi.org/10.1080/ 10474412.2020.1744446

Lecheler, S. (2020). The emotional turn in journalism needs to be about audience perceptions. Digital Journalism, 8(2), 287-291. https://doi.org/10.1080/ 21670811.2019.1708766

Lewis, S. C., \& Westlund, O. (2015). Actors, actants, audience, and activities in cross-media news work: A matrix and a research agenda. Digital Journalism, 3(1), 19-37. https://doi.org/10.1080/21670811. 2014.927986

Liu, Y. J. (2019). Positive emotional communication and cultural philosophy ecological construction under the background of intelligence media. Convivium, 36, 236-246. Retrieved from http://www. conviviumjournal.com/index.php/path/article/view/ 249

Madan, C. R. (2010). Neuromarketing: The next step in market research? Eureka, 1(1), 34-42. https://doi. org/10.29173/eureka7786

Mademlis, I., Mygdalis, V., Nikolaidis, N., Montagnuolo, M., Negro, F., Messina, A., \& Pitas, I. (2019). Highlevel multiple-UAV cinematography tools for covering outdoor events. IEEE Transactions on Broadcasting, 65(3), 627-635. https://doi.org/10.1109/TBC. 2019.2892585

Maier, S. R., Slovic, P., \& Mayorga, M. (2017). Reader reaction to news of mass suffering: Assessing the influence of story form and emotional response. Journalism, 18(8), 1011-1029. https://doi.org/10.1177/ 1464884916663597

Mañas-Viniegra, L., Veloso, A. I., \& Sierra-Sánchez, J. (2020). Contenidos inmersivos violentos: Investigación con eye tracking en jóvenes universitarios en España y Portugal [Immersive content with violence: A research using eye tracking with university students in Spain and Portugal]. El Profesional de la Información, 29(1), e290108. https://doi.org/10.3145/ epi.2020.ene.08

Marcos-Recio, J. C., Edo-Bolós, C., \& Parra-Valcarce, D. (2018). Remaining challenges for digital newspapers regarding informative updates: Case studies in the Spanish media. Communication \& Society, 31(2), 51-70. https://doi.org/10.15581/003.31.2.51-69

Mileti, A., Guido, G., \& Prete, M. I. (2016). Nanomarketing: A new frontier for neuromarketing. Psychology \& Marketing, 33(8), 664-674. https://doi.org/10.1002/ mar.20907

Morin, C. (2011). Neuromarketing: The new science of consumer behavior. Society, 48(2), 131-135. https:// doi.org/10.1007/s12115-010-9408-1

Orgeret, K. S. (2020). Discussing emotions in digital journalism. Digital Journalism, 8(2), 292-297. https://doi. org/10.1080/21670811.2020.1727347

Papacharissi, Z. (2015). Toward new journalism(s) affective news, hybridity, and liminal spaces. Journalism Studies, 16(1), 27-40. https://doi.org/10.1080/ 1461670X.2014.890328

Pieters, R., Warlop, L., \& Wedel, M. (2002). Breaking through the clutter: Benefits of advertisement originality and familiarity for brand attention and memory. Management Science, 48(6), 765-781. https:// doi.org/10.1287/mnsc.48.6.765.192

Ruiz-Collantes, F. X. (2008). Juegos y relatos como vivencias narrativas [Video games and discourses as narrative experiences]. In C. A. Scolari (Ed.), Homo videoludens (pp. 17-52). Vic: Eumo.

Rule, T. A. (2015). Airspace in an age of drones. Boston University Law Review, 95(1), 155-208. Retrieved from http://www.bu.edu/bulawreview/files/ 2015/02/RULE.pdf

Sacco, V., Gorin, V., \& Schiau, N. (2018). Immersive journalism and the migrant crisis: The case of Exils as a mobile radio reportage. Journal of Applied Journalism \& Media Studies, 7(1), 197-213. https://doi.org/ 10.1386/ajms.7.1.197_1

Sánchez-Laws, A. L. (2017). Can immersive journalism enhance empathy? Digital Journalism, 8(2), 213-228. https://doi.org/10.1080/21670811.2017.1389286

Sekander, S., Tabassum, H., \& Hossain, E. (2018). Multitier drone architecture for $5 \mathrm{G} / \mathrm{B} 5 \mathrm{G}$ cellular networks: Challenges, trends, and prospects. IEEE Communications Magazine, 56(3), 104-111. https://doi.org/ 10.1109/MCOM.2018.1700666

Sierra-Sánchez, J., Liberal-Ormaechea, S., \& MañasViniegra, L. (2020). The training in technology subjects of the future journalist in Spain. Revista Latina de Comunicación Social, 75, 189-206. https://doi. org/10.4185/RLCS-2020-1422en

Spaziante, L. (2018). Reality shootings: Indexicality and sensorial effectiveness, between eyewitness videos and news. Rivista Italiana di Filosofia del Linguaggio, 2017, 230-244. https://doi.org/10.4396/SFL201715

Stankov, U., Kennell, J., Morrison, A. M., \& Vujicic, M. D. (2019). The view from above: The relevance of shared aerial drone videos for destination marketing. Journal of Travel \& Tourism Marketing, 36(7), 808-822. https://doi.org/10.1080/10548408.2019.1575787

Sundar, S. K., Kang, J., \& Oprean, D. (2017). Being there in the midst of the story: How immersive journalism affects our perceptions and cognitions. Cyberpsychology Behavior and Social Networking, 20(11), 672-682. https://doi.org/10.1089/cyber.2017.0271

Tham, A., Selem, W., \& Ogulin, R. (2017). Taming the wicked problem of a drone ecosystem. The role of the media. Emergence-Complexity \& Organization, 19(3). https://doi.org/10.emerg/10.17357. 
bacc2e084836724ce105044a1486179a

Varan, D., Lang, A., Barwise, P., \& Bellman, S. (2015). How reliable are neuromarketers' measures of advertising effectiveness: Data from ongoing research holds no common truth among vendors. Journal of $\mathrm{Ad}$ - vertising Research, 55(2), 176-191. https://doi.org/ 10.2501/JAR-55-2-176-191

Wahl-Jørgesen, K. (2020). An emotional turn in journalism studies? Digital Journalism, 8(2), 175-194. https://doi.org/10.1080/21670811.2019.1697626

\section{About the Authors}

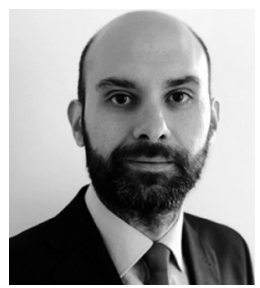

Luis Mañas-Viniegra (PhD) is Professor and Researcher in the Department of Applied Communication Studies at Complutense University of Madrid. He holds a PhD in Audiovisual Communication and Advertising with Extraordinary Award from the same University. He has been Professor at Carlos III University of Madrid, King Juan Carlos University and University of Valladolid. He is bachelor in Journalism and Advertising and Public Relations, and he is a member of the Complutense Research Group of Branding and Integrated Communication.

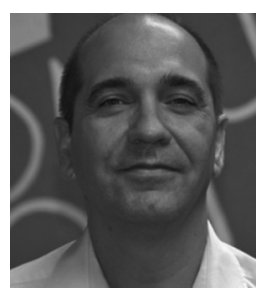

Alberto García-García (PhD) is a Lecturer of Television Technology at the Faculty of Media and Communication at the Complutense University of Madrid since 2006. For more than 15 years, he worked in sports transmissions of 'La Liga' as a relay operator. He has taught different specialization courses in live TV transmission techniques. His research interests focus on new technologies in television production, UHD (Ultra High Definition), Virtual Reality (which was the subject of his doctoral thesis presented in 2000), post-production and the use of drones.

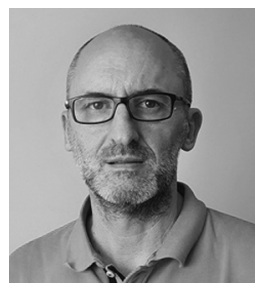

Ignacio J. Martín-Moraleda (PhD) is an Associate Professor of Audiovisual Communication and Advertising at the CAP Department in the Complutense University of Madrid where he serves as a researcher in technology media, production and realization systems. Counting over twenty-five years of professional experience in radio-tv projects, management, and data mining. He has participated in a lot of projects in advertising and media companies in different countries. 